\title{
Conversar para Relembrar em Família
}

\author{
Lídia Suzana Rocha de Macedo ${ }^{1}$ \\ Programa de Pós-Graduação em Psicologia da Universidade Federal do Rio Grande do Sul, \\ Porto Alegre, RS, Brasil \\ Tania Mara Sperb \\ Universidade Federal do Rio Grande do Sul, Porto Alegre, RS, Brasil
}

\section{Resumo}

A vida em família modifica-se em função de avanços tecnológicos e das transformações nas interações entre as pessoas, o que cria novos desafios para o estabelecimento de uma comunicação familiar eficiente e de boa qualidade. $\mathrm{O}$ artigo examina a influência de um tipo particular de comunicação familiar, o relembrar experiências pessoais. Analisam-se pesquisas que indicam que a maneira parental de relembrar está relacionada ao desenvolvimento de crianças e pré-adolescentes, em especial, da memória autobiográfica; mas também ao apego, à compreensão sobre o self, o outro e a mente, à regulação de emoções, ao desenvolvimento da autoestima e de habilidades pró-sociais e ao ajustamento psicológico. Apresentam-se pesquisas que mostram o que fazem os pais durante a conversação que pode influenciar positivamente o desenvolvimento de crianças e pré-adolescentes. Tecem-se considerações sobre o modo de estimular esse tipo de conversação nos contextos de crianças institucionalizadas, de centros de saúde e nas escolas.

Palavras-chave: Comunicação familiar, memória autobiográfica, narrativa autobiográfica, self, regulação de emoções.

\section{Talking to remember in Family}

\begin{abstract}
Life in family changes due to technological advances as well as to transformations in people's interactions. Therefore, new challenges to establish efficient and good quality family communication are created. The article deals with the influence of a particular family communication, i.e., the recall of personal experiences. A number of investigations indicating that the way parents recall is related to the development of children and preadolescents, especially to the development of autobiographical memory, is examined. Moreover, it is analysed its relationship to attachment, to the comprehension of the self, the other and the mind, to emotion regulation, to the development of self-esteem and prosocial abilities, and to psychological adjustment. Studies showing what parents do during conversation, which may positively influence the development of children and preadolescents are presented. Ways of stimulating this type of conversation in contexts of institutionalized children, health centers, and schools are discussed.
\end{abstract}

Keywords: Family communication, autobiographical memory, autobiographical narrative, self, emotion regulation.

Endereço para correspondência: Universidade Federal do Rio Grande do Sul, Instituto de Psicologia, Departamento de Psicologia do Desenvolvimento e da Personalidade, Rua Ramiro Barcelos, 2600, Santana, Porto Alegre, RS, Brasil 90035-003. Fone: (51) 3308-5246; Fax: (51) 3308-5473. E-mail: lidiasrmacedo@, gmail.com e sperbt@terra.com.br

Agência de financiamento: Conselho Nacional de Desenvolvimento Científico e Tecnológico (CNPq). 


\section{Conversar para Recordar en Familia}

\section{Resumen}

La vida familiar se ha modificado debido a los avances tecnológicos y los cambios en las interacciones entre las personas, creando nuevos retos para el establecimiento de una comunicación familiar efectiva y de calidad. El artículo examina la influencia de un tipo particular de comunicación familiar, el recordar experiencias personales. Se analizan los estudios que indican cómo este tipo de comunicación se relaciona con el desarrollo de los niños y pre-adolescentes, en particular, con la memoria autobiográfica, tambiem com el apego, la comprensión de uno mismo, del otro y de la mente, la regulación de las emociones, la autoestima y las habilidades prosociales y el ajuste psicológico. Se presentam investigaciones que muestran qué hacen los padres durante la conversación que influe positivamente en el desarrollo de niños y pre-adolescentes y formas de estimular este tipo de conversación en los contextos de niños internados en instituciones, centros de salud y escuelas.

Palabras clave: Comunicación familiar, memoria autobiográfica, narración autobiográfica, sí mismo, regulación de las emociones.

Em diversos espaços sociais têm-se escutado a mesma constatação: há uma forte tendência ao isolamento nas famílias de hoje. Até a primeira metade do século passado, os momentos de convivência familiar se caracterizavam por muitas atividades em comum. Famílias, não somente aquelas com crianças pequenas, iam juntas à igreja, ao clube e aos lares de outras famílias com quem conviviam, o que incluía a vizinhança. Em casa, durante as refeições, além da presença de todos, havia uma preocupação em acompanhar ativa ou passivamente (escutando, sem interromper) os tópicos discutidos à mesa, geralmente, conduzidos por adultos. Ao menos nos centros urbanos de culturas ocidentais, esse modelo está muito distante do modo de vida vigente hoje nas famílias, em particular, da maneira de se comunicar com o outro. Paulatinamente, o progresso conduz a mudanças nos modos de vida do passado. Cabe refletir, contudo, sobre o que seria conveniente preservar na jornada em direção ao futuro.

Atualmente, o tempo reservado para estar com a família tende a ficar restrito às refeições em comum, o que não garante a ocorrência de conversações. Em pesquisa realizada em Curitiba, que investigou crianças e adolescentes (7 a 17 anos) das classes alta e baixa, foi verificada a presença maciça da TV ligada durante as refeições em família, as quais ocorrem, preferen- cialmente, nos finais de semana (Gomide, Bussadori, Sabbag, Berri, \& Furtado, 2003). Já em pesquisa realizada em Porto Alegre, que investigou 189 famílias de classe média com um filho pré-adolescente, foi constatado o hábito diário de fazer as refeições em conjunto, mas $67,3 \%$ dos pré-adolescentes informaram que costumam fazer as refeições com a TV ou o computador ligados (Macedo, 2011). Como se constata, o fato da família estar reunida para uma refeição não significa que haverá alguma interação conversacional, pois seus membros podem estar envolvidos em interações virtuais (com a TV, celular, computador). Essas transformações da chamada era digital afetaram a maneira da família se comunicar e isso poderá ter repercussões no desenvolvimento de crianças e adolescentes e no ciclo vital da família.

Greenfield (2012) afirma que a substituição da comunicação no contexto da interação pessoal por interações virtuais (torpedos ou internet) acarreta a perda de muitos aspectos da interação pessoal que são importantes para a formação de uma pessoa capaz de sentir empatia, ter insights e compreender contextos. A neurocientista explica que a comunicação no contexto das interações pessoais produz tipos de mudanças cerebrais diferentes daquelas decorrentes da interação entre pessoa e computador ou na comunicação no contexto de interações virtuais. 
Desde uma perspectiva teórica evolucionista, já ocorreram mudanças consideráveis no cérebro como resultado dos processos de seleção natural. Segundo Donald (1991), a mente humana passou por uma série de adaptações e cada uma delas conduziu à emergência de um novo sistema representacional. Contudo, sucessivamente, cada sistema representacional anterior permanece intacto em nossa arquitetura mental atual de modo que a mente moderna é estruturada como um mosaico formado de vestígios dos estágios anteriores. Esta proposição se alinha a outro princípio da evolução, a conservação das aquisições prévias na adaptação. Essa teoria destaca a percepção dos eventos e decorrente formação da memória episódica como marca definidora do desenvolvimento mental humano. Humanos podem relembrar voluntariamente dos eventos.

A memória episódica é responsável pelas memórias associadas a um lugar e tempo específicos (Bauer, 2007). Ela permite, por exemplo, lembrar o lugar onde o carro foi deixado no estacionamento de um shopping na saída do cinema. Porém, apenas as memórias episódicas com um significado especial permanecem armazenadas por mais tempo e, dentre essas, somente aquelas que tiverem relevância para o self de um indivíduo farão parte de sua memória autobiográfica. Os dois tipos de memória servem a funções diferentes, como explicam Nelson e Fivush (2004). A memória para episódios específicos é crucial para antecipar e predizer situações no ambiente, sendo essencial à sobrevivência da espécie. Já a memória autobiográfica tem uma função sociocultural e é o que define o self no tempo e em relação aos outros. Pode-se pensar, então, que se a memória episódica é o sistema representacional que é marca definidora do desenvolvimento mental humano, a memória autobiográfica é o sistema para representar o próprio indivíduo ou a marca definidora de um desenvolvimento mental único.

Diversos autores têm buscado responder como se originam as memórias autobiográficas e quais os fatores que determinam sua emergência. Num extremo, há uma ênfase no desenvolvi- mento intrínseco da memória e em seus sistemas (Conway \& Pleydell-Pearce, 2000). No outro, destaca-se a influência da interação social e, em especial, do contexto do relembrar conjunto pais-criança (Nelson \& Fivush, 2004). Justamente é este contexto de conversação que pode estar ameaçado pelas transformações na comunicação familiar.

Durante os anos pré-escolares, segundo Nelson e Fivush (2004), a memória autobiográfica emerge e vem suplementar os sistemas de memória do início da vida. Isso se torna possível, devido a desenvolvimentos neurológicos que habilitam o desenvolvimento da memória e, em especial, da memória episódica. Na perspectiva das autoras supracitadas, o desenvolvimento da memória autobiográfica também é o resultado de um desenvolvimento interativo que inclui a aquisição de uma linguagem complexa, a produção e a compreensão de narrativas, a conversação para relembrar com pais e outros adultos, o estilo parental de relembrar, a compreensão do tempo e sobre o self, a perspectiva pessoal e a teoria da mente. Nesse artigo examina-se como se dá a influência do contexto do relembrar genitores-criança sobre um conjunto de habilidades que estão relacionadas ao sistema de memória autobiográfica, o qual continuará a se desenvolver por toda a vida.

\section{Relembrar Experiências Pessoais: Qual o Interesse nesse Tipo de Conversação?}

Relembrar em colaboração com os pais é um tipo de conversa que está descontextualizado da experiência imediata. É preciso dirigir a atenção para algo que não está presente fisicamente, o que implica em dispor de uma habilidade cognitiva sofisticada. Por essa razão, a criança precisa se apoiar na habilidade dos pais para resgatar a experiência (Fivush, Bohanek, \& Duke, 2008). O adulto fornece um suporte linguístico que ajuda a criança a focalizar sua atenção e organizar o evento em um todo coerente. Esse suporte linguístico é composto de perguntas, confirmações, incentivos, repetições e correções (Macedo \& Sperb, 2007). Perguntas específicas, 
como quem, o que, quando, porque e onde, fornecem uma estrutura para as histórias que encoraja a criança a fazer conexões entre os eventos (Peterson \& McCabe, 1994). Aqueles aspectos da experiência que tiverem sido linguisticamente estruturados pelo adulto serão melhor relembrados pela criança.

Essas oportunidades de reconstruir a experiência vivida com a ajuda da mãe e/ou do pai dirigem a atenção da criança para certos aspectos da experiência. Desse modo, elas também aprendem no que devem prestar a atenção quando estiverem em situações similares, a selecionar os aspectos do contexto que são considerados importantes e, como consequência, a como avaliar a experiência e quais são os aspectos a considerar positivos e quais negativos.

Esse tipo de conversação inicia logo que a criança torna-se uma usuária da linguagem, isto é, quando os pais começam a engajá-la em conversas sobre eventos passados e futuros ainda que, como referem Nelson e Fivush (2004), ela possa contribuir pouco. Durante os anos pré-escolares, a criança aprende a estruturar, relembrar e avaliar suas experiências ao participar dessas coconstruções que, segundo as pesquisas, ocorrem mais frequentemente com a mãe do que com o pai. Decorre daí, que a maior parte das investigações com crianças pequenas estuda o estilo materno de relembrar.

Em culturas ocidentais, como explica Fivush (2007), a maioria das mães costuma relembrar com os filhos as experiências compartilhadas, mas há diferenças claras na maneira de conduzir essas conversações. Há mães que apresentam um estilo altamente elaborador. Elas falam frequentemente sobre o passado e engajam seus filhos em longas e detalhadas conversações sobre o que aconteceu. Outras apresentam um estilo pouco elaborador. Essas mães não costumam falar sobre o passado com frequência e quando o fazem, tendem a fazer poucas perguntas e as repetem, algo que lembra um teste de memória. Fivush (2007) esclarece que as mães com estilo de relembrar altamente elaborador não são simplesmente mais falantes do que aquelas que apresentam um estilo pouco elaborador. $\mathrm{O}$ que as diferencia é que as primeiras se comportam de modo diferenciado durante o relembrar conjunto, mostrando que tentam alcançar objetivos específicos com a criança.

Resultados de pesquisas mostram que os genitores têm objetivos específicos nesse tipo de conversação. Fiese, Hooker, Kotary, Schwagler, e Rimmer (1995) constaram que ao compartilhar suas próprias experiências com um filho (1-4 anos), os genitores (91 pais e 97 mães) de crianças menores privilegiavam os temas de afiliação e das maiores, temas de autorrealização. A mudança nos temas pode derivar do interesse parental em facilitar a entrada na escola. Macedo (2011) investigou os hábitos conversacionais de 189 famílias brasileiras com filhos pré-adolescentes (10-13 anos). Os resultados mostraram que os genitores podem ter diferentes objetivos de conversação, que variam conforme a valência da experiência, e o gênero do filho pode ter influência sobre as mães. Os principais objetivos de conversação sobre experiências negativas foram resolução de problemas $(56,8 \%$ dos pais; $40,8 \%$ das mães), reforçar o self do pré-adolescente (6,8\% dos pais; $27,5 \%$ das mães) e fortalecer a relação (36,4\% dos pais; $31,7 \%$ das mães). Ao conversar sobre experiências positivas, os genitores optaram por reforçar o self do pré-adolescente ( $75 \%$ dos pais; $55,6 \%$ das mães), fortalecer a relação ( $15 \%$ dos pais; $29,4 \%$ das mães) e a resolução de problemas (10\% dos pais; $15 \%$ das mães). Os objetivos parentais não variaram ao longo dessa faixa etária (10-13 anos). Porém, as mães de meninas tenderam (resíduo ajustado $=1,6)$ a escolher a resolução de problemas $(21,7 \%)$ ao conversar sobre experiências positivas, em comparação com as mães de meninos $(7 \%)$.

Há pesquisas que investigaram a frequência do relembrar experiências pessoais em família e o interesse dos genitores e dos filhos nesse tipo de conversação. Quanto aos genitores de crianças pequenas (1-4 anos), Fiese et al. (1995) verificaram que a maioria (96\%) conversa, ao menos ocasionalmente, sobre as próprias experiências de infância. Numa pesquisa brasileira que investigou as conversas mães-criança (4-5 anos) na hora de dormir durante um mês, Macedo e Sperb (2008) verificaram que $46,2 \%$ das narra- 
tivas produzidas pelas crianças eram relatos de experiências pessoais. $\mathrm{O}$ mesmo ocorre com os genitores de pré-adolescentes e os próprios pré-adolescentes que costumam conversar em casa: estas conversas também são, principalmente, sobre experiências pessoais (Fivush et al., 2008; Macedo \& Sperb, 2013a). Em Fivush et al. (2008), a análise das conversas espontâneas da hora do jantar de 37 famílias norte-americanas com um filho pré-adolescente revelou que $66 \%$ das narrativas eram sobre as atividades do dia e 34\% eram narrativas sobre experiências passadas. Pré-adolescentes iniciavam mais frequentemente histórias sobre eventos compartilhados pela família. Já os genitores mais frequentemente iniciavam histórias sobre si mesmos quando crianças. Em famílias brasileiras de classe média, Macedo (2011) verificou que a maioria dos genitores ( $84 \%$ dos pais; $92,2 \%$ das mães) e dos pré-adolescentes (84\%) costuma conversar em casa sobre suas experiências pessoais, sendo que sentir emoções (positivas e negativas) é o que leva os pré-adolescentes a conversar em casa. Neste estudo, não foi encontrada associação entre gênero e hábito conversacional do pré-adolescente, mas foi verificada uma associação estatisticamente significativa entre hábito conversacional e idade dos pré-adolescentes, $\chi^{2}(3, n=189)=$ 10,$37 ; p=0,01$. À medida que a idade aumenta, diminui a porcentagem de pré-adolescentes que conta suas experiências em casa, o que sugere uma mudança nos hábitos de conversação com a entrada na adolescência.

Pré-adolescentes parecem precisar ainda de um interlocutor facilitador para narrar suas experiências envolvendo emoções. Fivush, Marin, McWilliams, e Bohanek (2009) deram instruções diferentes a dois grupos de pré-adolescentes ( $N=112 ; 9-13$ anos), uma estimulando uma escrita emocional (pensamentos e sentimentos mais profundos) e a outra não-emocional (um dia típico). Em três dias consecutivos, eles escreveram silenciosamente e individualmente durante 15-20 minutos. Antes dessa intervenção e dois meses após, os pré-adolescentes preencheram escalas de depressão, ansiedade, pontos fortes de sua personalidade e dificuldades, e sintomas psicossomáticos. Os resultados mostraram que, em comparação com o grupo de escrita não-emocional, os pré-adolescentes do grupo de escrita emocional escreveram mais sobre avaliações negativas, problemas, emoções, explanações e coping. Esses pré-adolescentes apresentaram níveis mais elevados de ansiedade, depressão e dificuldades dois meses após a intervenção. Para os autores, é possível que a escrita expressiva não seja benéfica para alguns pré-adolescentes, em função de limitações na habilidade narrativa e na regulação de emoções.

Durante a pré-adolescência, há uma evolução na habilidade narrativa impulsionada por novas habilidades cognitivas disponibilizadas com a aquisição do pensamento formal. Essas habilidades, entre outras coisas, irão permitir ao pré-adolescente começar a pensar interpretativamente a experiência vivida, e assim modificar sua maneira de narrar experiências (Mckeough $\&$ Genereux, 2003). Os resultados de Fivush et al. (2009) e os das pesquisas que compararam os estilos narrativos de pais e filhos na pré-adolescência (Peterson \& Roberts, 2003), e na adolescência (Zaman \& Fivush, 2011) podem estar refletindo essa evolução. Especificamente, podem estar assinalando a transição de um estilo narrativo apoiado no estilo dos pais para um estilo narrativo próprio, apoiado na nova habilidade para pensar e interpretar o vivido. Na pesquisa de Peterson e Roberts (2003), foram encontradas similaridades entre as narrativas de genitores e de seus filhos pré-adolescentes, sendo que essa é maior nas narrativas das filhas do que dos filhos e é maior nas díades mães e filhas de 13 anos. Já com relação a adolescentes, os resultados da pesquisa de Zaman e Fivush (2011), em que foi solicitado a 65 adolescentes (14-16 anos) que narrassem duas histórias sobre a infância da mãe e do pai e duas histórias pessoais positivas, indicaram que os adolescentes parecem narrar as experiências dos genitores através das lentes diferenciadas por gênero de seus genitores. Entretanto, as próprias experiências, eles narram segundo suas próprias lentes diferenciadas por gênero. É possível concluir, então, que até a adolescência, as histórias que os genitores contam sobre o próprio passado possuem um registro na memória dos filhos em seus respectivos estilos 
narrativos originais. Já os adolescentes quando narram suas próprias experiências, parecem tomar distância do estilo narrativo parental. Resultados que podem estar ilustrando o funcionamento do pensamento interpretativo.

Essas informações indicam que pode haver um período de maior influência da conversação familiar sobre experiências pessoais que inicia quando a criança se torna uma usuária da linguagem e tende a diminuir na pré-adolescência, quando aumenta a escolha dos amigos como parceiros para esse tipo de conversa (Macedo $\&$ Sperb, 2013a). Para os genitores de crianças e pré-adolescentes, esse tipo de conversa cria oportunidades de orientar os filhos, ajudá-los e estimulá-los a resolver conflitos, e fortalecer os vínculos. A criança e o pré-adolescente podem aproveitar as oportunidades de narrar a própria experiência em um contexto facilitador e acolhedor, e de escutar as experiências uns dos outros, o que aumenta a proximidade entre os membros da família.

\section{Conversar sobre Experiências Envolvendo Emoções}

A ligação entre as conversas entre a mãe e a criança pequena sobre experiências envolvendo emoções e o desenvolvimento posterior de habilidades da criança para reconhecer e lidar com emoções vem sendo investigada há mais de duas décadas. Um dos estudos pioneiros sobre o assunto foi desenvolvido por Dunn, Brown e Beardsall (1991). Estas autoras observaram as conversas sobre estados emocionais de crianças de três anos com a mãe e irmãos, em suas casas, e verificaram que as diferenças na maneira de conversar sobre emoções (frequência, discussão sobre causas, diversidade de temas e discussões) estavam relacionadas com a habilidade da criança aos seis anos para reconhecer emoções em uma tarefa de tomada de perspectiva emocional. Por sua vez, Laible (2004) enfatizou a importância de se considerar a especificidade do contexto do relembrar experiências envolvendo emoções. Em seu estudo, a autora comparou as elaborações maternas nos contextos do relembrar experiências envolvendo emoções e na leitura de histórias e encontrou que, apenas durante o re- lembrar experiências, as elaborações maternas foram preditoras da compreensão posterior da criança sobre emoções.

Concomitantemente, surgiram pesquisas cujos resultados mostraram que a dimensão mais importante em que o estilo materno de relembrar poderia variar tem a ver com o nível de elaboração utilizado pela mãe (Fivush, 2007). Foram encontradas associações entre o estilo materno de relembrar e vários desenvolvimentos da criança, como a memória autobiográfica, memória estratégica, linguagem e letramento, relacionamentos de apego, compreensão sobre o self, o outro e a mente, e a regulação de emoções da criança (Fivush, Haden, \& Reese, 2006; Fivush \& Nelson, 2004); o desenvolvimento de sua autoestima (Reese, Bird, \& Tripp, 2007); o desenvolvimento de habilidades pró-sociais, relações com os pares e ajustamento psicológico (Halberstadt, Denham, \& Dunsmore, 2001).

A forma como a participação da mãe e do pai nesse tipo de conversa pode ajudar o filho a lidar com emoções é tema de pesquisa de vários investigadores. Assim, vários deles passaram a estudar o que os pais faziam durante o relembrar conjunto que poderia trazer resultados positivos. Com crianças pré-escolares, encontraram que os resultados são mais positivos quando as conversações são abertas e integradas (Halberstadt et al., 2001); quando ao conversar sobre eventos negativos, a fala da mãe é controlada e ela envolve a criança através da alternância de turnos de fala (Burch, Austin, \& Bauer, 2004); quando os genitores explanam as causas e consequências das emoções e ajudam a criança a fazer conexões entre as emoções e outros estados mentais, o que vale para as conversas sobre experiências com emoções negativas e sobre experiências positivas (Bird \& Reese, 2006; Reese et al., 2007).

Já em famílias com pré-adolescentes, as pesquisas indicam que há diferenças no estilo materno e paterno de relembrar as quais repercutem no desenvolvimento dos filhos. Fivush et al. (2009) encontraram relações entre as elaborações e avaliações maternas sobre os fatos nos eventos negativos e níveis elevados de bem-estar no pré-adolescente e entre as elaborações e avaliações paternas sobre aspectos emocionais 
dos eventos positivos e dos eventos negativos e níveis mais baixos de bem-estar no pré-adolescente. Bohanek et al. (2009), por sua vez, investigaram as narrativas espontâneas durante as refeições familiares e encontraram correlações entre as contribuições das mães às narrativas sobre experiências compartilhadas e um menor número de comportamentos de internalização e externalização no pré-adolescente; e entre as contribuições dos pais às narrativas sobre experiências individuais e um número menor de comportamentos de internalização e externalização no pré-adolescente. Os resultados das duas pesquisas sugerem que pais e mães têm papéis diferentes nas construções narrativas com os filhos e que esse desempenho diferente dos genitores pode estar relacionado ao ajustamento emocional dos filhos.

Em estudo anterior, Bohanek, Marin, Fivush e Duke (2006) investigaram os estilos que as famílias adotam em suas conversações sobre experiências envolvendo emoções com filhos pré-adolescentes. A Análise de Clusters revelou três clusters que correspondem às perspectivas para entender o passado: individual, imposta e coordenada. A perspectiva individual se caracteriza por trocas desconectadas e por ser centrada no pré-adolescente. Na perspectiva imposta, um dos pais impõe sua perspectiva do evento sobre os outros membros da família, indica quem deve falar e o que deve ser falado. Há trocas desarmônicas que se caracterizam por chamar a atenção para si, impedir a expressão de emoções, negar emoções e repreender, comportamentos que servem para desqualificar a perspectiva da outra pessoa e impor a sua própria. A perspectiva coordenada se caracteriza por interações colaborativas em que todos os membros da família acrescentam diferentes fragmentos da história e expandem as contribuições dos outros membros, resultando em uma narrativa mais integrada, complexa e rica quando comparada àquela que um indivíduo seria capaz de produzir sozinho. Os resultados mostraram que esse é o único estilo que permite a integração de emoções, pensamentos e sentimentos de todos os membros da família. Assim, famílias que apresentaram esse estilo conversacional aceitam as coconstruções dos eventos passados e produzem uma perspectiva compartilhada do que realmente aconteceu. Os resultados também mostraram que essa perspectiva está correlacionada à autoestima elevada nas pré-adolescentes. Contudo, o fato de não ter sido encontrado resultado semelhante nos pré-adolescentes precisa ser melhor investigado.

Os meios pelos quais a conversação entre os genitores e seus filhos (crianças ou pré-adolescentes) sobre experiências envolvendo emoções pode ajudá-los a lidar com emoções também mereceram a atenção dos pesquisadores. Então, encontrou-se que a maneira como o adulto conversa com a criança para relembrar uma experiência envolvendo uma emoção influencia a maneira como ela vai relembrar a experiência em que viveu essa emoção específica (Burch et al., 2004; Fivush, 1991), o que por sua vez irá influenciar a maneira de lidar com essa emoção subsequentemente. Essa influência fica clara no desenvolvimento de duas das estratégias para regular emoções que têm sido consideradas especialmente eficazes: o controle da atenção e a reavaliação cognitiva (Ochsner \& Gross, 2005). Segundo Troy e Mauss (2011), o controle da atenção eficaz envolve usar seletivamente a atenção retirando-a dos estímulos negativos irrelevantes e dirigindo-a para estímulos mais positivos ou neutros. Ao filtrar a informação, deixando de fora a negativa irrelevante, é mais provável que os indivíduos façam avaliações menos ameaçadoras da situação estressante e como resultado experimentem menos emoções negativas, o que por sua vez provavelmente aumenta a resiliência. Desde cedo no desenvolvimento, os pais buscam reduzir a experiência da criança pequena com emoções negativas dirigindo sua atenção para estímulos neutros ou prazerosos (p. ex.: retirar a tesoura da mão da criança, enquanto se chama sua atenção para uma borboleta colorida no jardim), assim como fornecendo reavaliações da experiência para a criança (p. ex.: diante de uma situação triste dizer que não foi nada, não foi por querer, ele não fez por mal, vai passar). $\mathrm{O}$ contexto das conversas sobre experiências com emoções negativas com a criança em idade pré-escolar oportuniza aprendizagens cognitivamente mais sofisticadas, o que permite 
que a criança passe a exercitar um papel ativo no controle seletivo da atenção e seja autora de reavaliações.

Quando a criança vive uma experiência que provoca fortes emoções, relembrar dela com a ajuda do adulto pode auxiliá-la a compreendê-la melhor, o que irá se refletir em suas narrativas posteriores sobre o evento e repercutir em seu bem-estar-psicológico. Sales, Fivush, Parker e Bahrick (2005) examinaram 35 crianças de 3 a 4 anos imediatamente após a passagem do furacão Andrew (EUA, Flórida, 1992) e novamente quando as crianças tinham 9 e 10 anos. Nos dois momentos, as crianças foram entrevistadas e foi utilizada a escala de sintomatologia do Transtorno de Stress Pós-traumático (PTSD). As mães preencheram um questionário com respostas em escala Likert para estabelecer a quantidade de conversação familiar, em três momentos (imediatamente após a passagem do furacão, num período subsequente e no último ano) com o objetivo de saber sobre a preparação para o furacão, sobre o que ocorreu durante sua passagem e após. Os resultados sugerem que a habilidade e a prontidão da criança para fornecer informações durante a recordação livre foram os melhores preditores de seu bem-estar psicológico imediatamente após o furacão. As autoras argumentam que as crianças que forneceram mais informações durante a recordação livre e recordaram mais informações gerais sobre a experiência imediatamente após o furacão podem ter tido uma compreensão melhor sobre o evento. Essa compreensão, que provavelmente foi favorecida pelas conversações com a mãe, possivelmente facilitou um melhor funcionamento psicológico depois da experiência traumática.

O hábito familiar de conversar sobre experiências envolvendo emoções também parece ajudar pré-adolescentes a regular a raiva. Em uma pesquisa brasileira recente, foi investigada a regulação de emoções em pré-adolescentes (10-13 anos) que costumam e que não costumam compartilhar suas experiências pessoais em casa (Macedo \& Sperb, 2013b). Os resultados mostraram que o contexto da conversação familiar sobre experiências envolvendo emoções está significativamente relacionado ao desenvolvi- mento de estratégias mais sofisticadas para lidar com a raiva, tais como as reavaliações cognitivas, $\chi^{2}(1)=6,60 ; p<0,01$.

Considerando-se essas informações, observa-se que a maneira familiar de acolher e de conversar sobre as experiências envolvendo emoções dos filhos possivelmente tem neles implicações profundas, influenciando em como lidam com suas emoções e em seus ajustamentos psicológicos. Esse tipo de conversação participa da visão que a criança, ou o pré-adolescente, desenvolve de si mesmo, baseada em como ele percebe que sua família o vê e no conjunto de histórias que ele conta e ouve sobre si, sobre as quais se construíram significados, tópico detalhado a seguir.

\section{A Noção de um Eu que Continua: Self, Memória Autobiográfica e Narrativa Autobiográfica}

Particularidades no contexto do relembrar pais-criança acionam e desenvolvem diferentes tipos de processamento cognitivo na criança, os quais propiciam o desenvolvimento de uma compreensão maior sobre a mente, o próprio self e o outro. Fivush e Nelson (2004) descreveram cinco aspectos do relembrar pais-criança e suas repercussões no desenvolvimento futuro.

1. As negociações entre os pais e a criança durante o relembrar de eventos ocorridos no passado conduzem ao desenvolvimento de uma teoria representacional da memória. Nas conversações em que algo é relembrado com a criança podem ocorrer confrontações, o que facilita o início, ao redor dos 3 anos, da compreensão de que as memórias são representações, ao invés de cópias fiéis dos eventos passados. A participação nesse tipo de conversa leva, assim, à descoberta de que mesmo vivendo a mesma experiência as pessoas podem recordar e/ou esquecer diferentes aspectos dela.

2. O uso parental de termos para referir os estados internos da criança possibilita que ela coordene como se sentiu no passado (o self do passado) a como se sente no presente (o self do presente). Isto propicia que a criança 
desenvolva a noção de um self que tem continuidade no tempo.

3. O uso parental de termos para referir os estados internos de outros enseja que ela coordene como o outro se sentiu no passado e como se sente no presente. A criança, então, começa a compreender que o outro também tem uma existência continuada no tempo.

4. As negociações sobre estados internos já experimentados permite que a criança coordene o self do passado ao outro no passado, o que conduz ao desenvolvimento de uma teoria da memória que inclui perspectivas. A criança passa a compreender que se pode discordar sobre emoções, pensamentos e avaliações relativas às experiências. Como resultado, ela passa a compreender que tanto ela quanto o outro possuem perspectivas singulares sobre o evento passado.

5. A aprendizagem da estrutura narrativa introduz um esquema explicativo de causalidade para compreender a experiência. Em termos de processamento cognitivo, a estrutura narrativa permite à criança coordenar estados internos com motivação e comportamento. Ao narrar suas experiências em colaboração com os genitores, ela tem oportunidades para discutir, comparar, negociar estados internos do self e do outro, e de situar esses estados internos em narrativas que explicam comportamentos. Assim, desenvolve-se na mente da criança uma noção do self e do outro, como entidades psicológicas que se mantêm no tempo. O desenvolvimento da memória autobiográfica tem uma relação de estreita dependência com o desenvolvimento dessa noção do self como uma existência continuada no tempo. Isso porque a memória autobiográfica agrega as experiências significativas do passado e as integra em uma história pessoal em que o self do passado, do presente e do futuro estão relacionados (Habermas \& Bluck, 2000; McAdams, 2001).

É importante salientar também que a memória autobiográfica, de acordo com Fivush (2011), é um tipo de atividade cultural e como tal é individual e se desenvolve nas interações dentro de um contexto social e cultural específicos. A cultura define quais habilidades são necessárias para alguém se tornar um de seus membros e, consoante com esse objetivo, organiza atividades em que as crianças podem desenvolver tais habilidades em contextos da prática guiada por adultos. Especificamente, a importância que uma determinada cultura dá à memória autobiográfica pode ser observada no tipo de atividades que os adultos organizam para as crianças pequenas e nas quais esperam que elas se engajem. Como exemplo, pode-se citar quando um pai pede a uma criança de dois anos que ela conte o que fez na escola.

Assim, o que é escolhido para ser dito ou não dito durante as conversações sobre experiências pessoais emerge das relações que o narrador tem com as pessoas que o estão ouvindo e das pessoas com quem está relembrando, ou seja, as memórias de experiências pessoais são moduladas pela reminiscência com os outros (Fivush, 2008). Esse contexto conversacional é crítico para o desenvolvimento da memória autobiográfica e para o desenvolvimento das narrativas autobiográficas. Pesquisas mostram que mães que engajam a criança num relembrar altamente elaborador têm crianças que produzem narrativas autobiográficas mais coerentes e emocionalmente mais expressivas, têm melhor compreensão a respeito do próprio self e maior habilidade para regular emoções do que as crianças cujas mães são menos elaboradoras ao relembrar (Fivush, 2007).

Ao longo do desenvolvimento, esse tipo de conversações auxilia a criança a compreender que algumas experiências são mais self relevantes do que outras (Bauer, 2007). Em consequência, torna-se possível construir uma narrativa autobiográfica com experiências realmente self relevantes. E a aquisição do pensamento formal, ao redor dos 11 anos, amplia os recursos cognitivos necessários ao pré-adolescente para construir uma narrativa sobre sua história pessoal. Eles adquirem, por exemplo, maior capacidade para compreender e refletir sobre as próprias experiências e podem relacionar as experiências dos outros à sua própria (Habermas \& Bluck, 2000). 
Nessa linha, Macedo (2011) comparou as narrativas autobiográficas de pré-adolescentes (11-13 anos) que costumam e que não costumam compartilhar experiências pessoais em casa. A análise das narrativas revelou que os que costumam compartilhar experiências pessoais possuem maior habilidade para avaliar suas experiências e lidar com as emoções que as acompanham; têm maior habilidade para selecionar experiências self-relevantes e encaixá-las em uma linha de continuidade; e têm também maior conhecimento sobre o próprio self. Assim, de acordo com os resultados, os pré-adolescentes que costumam conversar em casa alcançaram benefícios que aqueles que não costumam conversar não obtiveram.

O hábito de conversar sobre experiências pessoais em casa permite ainda que as histórias individuais sejam encaixadas no contexto mais amplo das histórias familiares. Como explicam Fivush et al. (2008), estas histórias individuais influenciam como se desenvolve e se pode compreender a própria identidade narrativa emergente. Contar e compartilhar a história familiar leva o pré-adolescente a desenvolver um senso de self conectado às gerações anteriores. Ancorar a própria história na história familiar possibilita, que ao sair da infância, o pré-adolescente possa sentir-se mais situado e seguro.

A emergência da adolescência ainda trará mais mudanças pois duas capacidades previamente independentes - relembrar o passado e compreender as pessoas - são coordenadas e o resultado disso é uma percepção crescente de que o passado não é simplesmente o que está armazenado, mas algo que requer interpretação (Habermas \& Paha, 2001).

A ligação entre memória autobiográfica, narrativa autobiográfica e compreensão sobre o próprio self no contexto de conversações em que memórias são compartilhadas permanece mesmo na vida adulta. Há evidências empíricas de que as conversações em que são relembradas memórias autobiográficas influenciam as visões atuais que adultos têm do próprio self (Wilson \& Ross, 2003).

\section{Considerações Finais}

Conforme essa revisão, a presença de um espaço para a narrativa de experiências pessoais na família está relacionada ao desenvolvimento saudável de crianças e pré-adolescentes. Esse pode ser um contexto ideal para o exercício do que Zanetti e Gomes (2011) chamaram modo consistente de parentalidade. Isso porque relações hierárquicas não-autoritárias podem ser reforçadas, na medida em que o lugar e a função de cada um no grupo familiar são estabelecidos e respeitados. Quando uma experiência pessoal é compartilhada, o narrador tem a oportunidade de explicar sua perspectiva dos fatos, podendo os demais validá-la ou não, ou seja, pode haver uma negociação em torno dos significados da experiência.

Ao narrar suas experiências, os pais compartilham com os filhos sua visão de mundo, o que deixa mais claro o estabelecimento de regras e limites. O relato do filho, por sua vez, permite aos pais acompanhar a evolução da sua compreensão sobre o mundo e, com base nessa, fazer os ajustes necessários na função parental. Esse contexto, portanto, ajuda os pais no exercício da parentalidade, ao facilitar situar e ressituar pais e filhos em suas posições em cada momento do desenvolvimento dos filhos, o que aumenta as chances de êxito dos pais para lidar com desafios futuros, como os que caracterizam a adolescência.

Instrumentalizar os pais para melhorar sua comunicação com os filhos pode ser uma ação estratégica interessante. Informar e discutir o tema com os profissionais da área da saúde e da educação pode ajudar esses profissionais a identificar famílias que apresentam padrões e esquemas de comunicação familiar sem abertura e sem acesso às emoções (Fitzpatrick \& Koerner, 2005) ou sem as condições necessárias na família para que falantes e ouvintes possam se expressar, escutar uns aos outros, compreender-se e aos outros e se beneficiar com essas trocas (Olson, 2003). Algumas famílias podem precisar de uma abordagem terapêutica, mas a maioria delas pode se beneficiar com estratégias de pre- 
venção, como a participação em grupos de pais (genitores) e grupos de mães orientados por profissionais habilitados.

Já crianças podem aproveitar espaços para a produção e escuta de narrativas pessoais e ficcionais em escolas e abrigos. Em uma escola de educação infantil de Porto Alegre, foram realizadas oficinas com crianças de seis anos com o objetivo de promover a construção individual e coletiva de narrativas de vários gêneros (Smith, Bordini, \& Sperb, 2009). Foi contatado que as crianças narram mais nos contextos informais, em comparação com os contextos de fala eliciada e apoiada pela professora. As pesquisadoras observaram a necessidade das crianças de narrar experiências de seu cotidiano e a não valorização desse tópico nos contextos de fala eliciada. No Recife, oito crianças (6-8 anos) acolhidas em um abrigo participaram de uma atividade de hora do conto semanalmente durante oito meses (De Conti \& Bezerra, 2013). A ideia era que a leitura dos contos estimulasse a produção de narrativas. Os resultados mostraram que as crianças se apropriaram dos recursos esquemáticos presentes nos contos narrados e acrescentaram a esses outras características e situações. Para De Conti e Bezerra, os resultados ilustram o movimento da criança que parte dos cânones narrativos da cultura na direção da autoria de narrativas e de sua própria história.

Pré-adolescentes e adolescentes podem se beneficiar de grupos de conversação sobre experiências difíceis, como desempenho escolar baixo, separação dos pais, morte de familiares e vivências de grandes desastres (enchentes, desmoronamentos, incêndios). Esses temas aparecem nas narrativas de pré-adolescentes (Macedo, 2011) e costumam ser acompanhados por um sofrimento solitário que pode se intensificar e gerar problemas futuros.

A escola pode ainda oportunizar para adolescentes grupos de conversação sobre temas importantes como sexualidade e gênero. Numa escola de ensino médio de Porto Alegre, Bordini e Sperb (2012) propuseram grupos de discussão em um espaço virtual (MSN) para discutir questões relacionadas à construção da identidade de gênero. Foram formados 6 grupos de adolescen- tes (14-15 anos), totalizando 41 participantes. Os resultados mostraram uma predominância dos padrões tradicionais de gênero. Já em uma escola especial para deficientes auditivos, Bisol (2008) investigou as especificidades da construção de significados e sentidos para a dimensão da sexualidade em adolescentes surdos. Foram analisadas as narrativas autobiográficas de 32 adolescentes surdos sobre suas vivências amorosas. Para Bisol, as narrativas mostraram-se adaptadas ao repertório cultural de significados e constituem-se como tentativas de dar significado ao vivido. Ambas as pesquisas evidenciam a necessidade do adolescente de ter um espaço adequado para conversar sobre esses temas.

Criar esse tipo de oportunidade para crianças e adolescentes que vivem em situação de rua ou em abrigos é um desafio a ser enfrentado. Essa revisão mostra que o hábito de conversar sobre as próprias experiências com os pais (ou adultos significativos) é fundamental para a formação da memória autobiográfica, que ajuda a definir o self no tempo. Pesquisas (Ferreira, Littig, \& Lescovi, 2014; Ribeiro \& Ciampone, 2002) mostram que crianças e adolescentes que vivem em abrigos ou em situação de rua têm dificuldades para se situar no tempo. Ribeiro e Ciampone (2002) verificaram que as crianças não sabiam qual era o dia da semana, o que atribuíram à percepção de dias muito iguais uns aos outros. Elas não sabiam a quanto tempo estavam no abrigo; quando haviam sido institucionalizadas e, muitas vezes, quando era o próprio aniversário. Fugas frequentes e a estada em diferentes abrigos agravam a perda de referências. Em Vila Velha, Ferreira et al. (2014) entrevistaram 14 crianças e adolescentes (10-17 anos) que viviam antes em situação de rua. Constataram o mesmo tipo de alteração nas noções de tempo e espaço que a pesquisa supracitada. As duas pesquisas apresentam evidências empíricas claras da dificuldade para organizar a própria história de vida, o que atesta a necessidade de trabalhar com dispositivos que auxiliem a desenvolver a memória autobiográfica e a construir a percepção de um eu que continua no tempo.

A criação de espaços de conversação em abrigos pode ainda melhorar o vínculo da crian- 
ça e do adolescente com a instituição. Essa poderia ser uma forma de romper com o círculo vicioso que tem sua origem no caráter transitório e provisório dos abrigos, que resulta no estabelecimento de vínculos breves e superficiais, o que por sua vez contribui para que crianças optem por se manter nas ruas (Arpini, 2003; Ribeiro \& Ciampone, 2002) ou circulem entre os abrigos.

Numa direção semelhante, porém, para ilustrar o momento sociohistórico de nossa civilização, Mia Couto (2014) usou a metáfora de uma cobra sem cabeça e sem cauda. Explicou que é como se não existisse passado ou futuro, restando-nos apenas a efemeridade do presente. Presente que se caracteriza por um contínuo movimento a espera do que ainda virá. Contudo, o novo já nasce fadado a ser substituído, assim que chega a próxima novidade. Ele propôs que para semear o futuro é preciso guardar memórias e contar histórias, pois "não somos nós que guardamos nossas memórias, mas elas é que nos guardam e protegem". É oportuno, portanto, cultivar o contexto da conversação para relembrar durante o desenvolvimento, para chegar à construção de memórias e de significados para o vivido e para a própria existência.

\section{Referências}

Arpini, D. M. (2003). Repensando a perspectiva institucional e a intervenção. Psicologia Ciência e Profissão, 21(3), 70-75.

Bauer, P. (2007). Remembering the times of our lives: Memory in infancy and beyond. Mahwah, $\mathrm{NJ}$ : Lawrence Erlbaum.

Bird, A., \& Reese, E. (2006). Emotional reminiscing and the development of an autobiographical self. Developmental Psychology, 42(4), 613-626. doi:10.1037/0012-1649.42.4.613

Bisol, C. A. (2008). O adolescer no contexto da surdez: Questões sobre a sexualidade (Tese de doutorado, Instituto de Psicologia, Universidade Federal do Rio Grande do Sul, Porto Alegre, RS, Brasil)

Bohanek, J., Fivush, R., Zaman, W., Lepore, C. E., Merchant, S., \& Duke, M. P. (2009). Family dinner time conversations. Merrill-Palmer Quarterly, 55(4), 488-515. doi:10.1353/mpq.0.0031
Bohanek, J., Marin, K., Fivush, R., \& Duke, M. (2006). Family narrative interaction and children's sense of self. Family Process, 45(1), 3954. doi:10.1111/j.1545-5300.2006.00079.x

Bordini, G., \& Sperb, T. M. (2012). Concepções de gênero nas narrativas de adolescentes. Psicologia: Reflexão e Crítica, 25(4), 738-746. doi:10.1590/S0102-79722012000400013

Burch, M., Austin, J., \& Bauer, P. (2004). Understanding the emotional past: Relations between parent and child contributions in emotionally negative and nonnegative events. Journal of Experimental Child Psychology, 89, 276-297. doi:10.1016/j.jecp.2004.07.006

Conway, M., \& Pleydell-Pearce, C. (2000). The construction of autobiographical memories in the Self-Memory System. Psychological Review, 107(2), 261-288. doi:10.1037/0033295X.107.2.261

Couto, M. (2014, $1^{\circ}$ set.). Guardar memórias, contar histórias e semear o futuro. Conferência ministrada como Aula Magna, Universidade Federal do Rio Grande do Sul, Porto Alegre, RS, Brasil.

De Conti, L., \& Bezerra, I. (2013). Contos e narrativas infantis: Análise das lógicas de organização narrativa. In A. Roazzi \& T. M. Sperb (Eds.), $O$ desenvolvimento de competências sociocognitivas: Novas perspectivas (pp. 37-61). São Paulo, SP: Vetor.

Donald, M. (1991). Origins of the modern mind: Three stages in the evolution of culture and cognition (pp. 159-200). Cambridge, MA: Harvard University Press.

Dunn, J., Brown, J., \& Beardsall, L. (1991). Family talk about feelings states and children's later understanding of others' emotions. Developmental Psychology, 27(3), 448-455. doi:10.1037/00121649.27.3.448

Ferreira, V. V. F., Littig, P. M. C. B., \& Vescovi, R. G. L. (2014). Crianças e adolescentes abrigados: Perspectiva de futuro após situação de rua. Psicologia \& Sociedade, 26(1), 165-174. doi:10.1590/S0102-71822014000100018

Fiese, B., Hooker, K. A., Kotary, L., Schwagler, J., \& Rimmer, M. (1995). Family stories in the early stages of parenthood. Journal of Marriage and Family, 57(3), 763-770.

Fitzpatrick, M. A., \& Koerner, A. F. (2005). Family communication schemata: Effects in children's 
resiliency. In S. Dunwoody, L. B. Becker, D. McLeod, \& G. Kosicki (Eds.), The evolution of key mass communication concepts: Honoring Jack M. McLeod (pp. 115-139). Cresskill, NJ: Hampton Press.

Fivush, R. (1991). The social construction of personal narratives.Merrill-PalmerQuartely, 37(1),59-82.

Fivush, R. (2007). Maternal reminiscing style and children's developing understanding of self and emotion. Clinic Social Work Journal, 35, 37-46. doi:10.1007/s10615-006-0065-1

Fivush, R. (2008). Remembering and reminiscing: How individual lives are constructed in family narratives. Memory Studies, 1(1), 49-58. doi: $10.1177 / 1750698007083888$

Fivush, R. (2011). The development of autobiographical memory. Annual Review of Psychology, 62, 559-582. doi:10.1146/annurev. psych.121208.131702

Fivush, R., Bohanek, J. G., \& Duke, M. (2008). The intergenerational self: Subjective perspective and family history. In F. Sani (Ed.), Individual and collective self-continuity (pp. 131-144). Mahwah, NJ: Erlbaum.

Fivush, R., Haden, C., \& Reese, E. (2006). Elaborating on elaborations: Role of maternal reminiscing style in cognitive and socioemotional development. Child Development, 77(6), 1568-1588. doi:10.1111/j.1467-8624.2006.00960.x

Fivush, R., Marin, K., McWilliams, K., \& Bohanek, J. G. (2009). Family reminiscing style: Parent gender and emotional focus in relation to child well-being. Journal of Cognition and Development, 10(3), 210-235. doi:10.1080/15248370903155866

Fivush, R., \& Nelson, K. (2004). Culture and language in the emergence of autobiographical memory. Psychological Science, 15(9), 573577. doi:10.1111/j.0956-7976.2004.00722.x

Gomide, P., Bussadori, D., Sabbag, G., Berri, G., \& Furtado, M. (2003). A influência da TV e dos estilos parentais nos horários de refeição das famílias. Psicologia Argumento, 21(32), 27-35.

Greenfield, S. (2012, 17 set.). O futuro do cérebro, o cérebro do futuro. Conferência ministrada no seminário Fronteiras do Pensamento, Universidade Federal do Rio Grande do Sul, Porto Alegre, RS, Brasil.
Habermas, T., \& Bluck, S. (2000). Getting a life: The emergence of the life story in adolescence. Psychological Bulletin, 126, 748-769. doi:10.1037/0033-2909.126.5.748

Habermas, T., \& Paha, C. (2001). The development of coherence in adolescents' life narratives. NarrativeInquiry, 11,35-54.doi:10.1075/ni.11.1.02hab

Halberstadt, A., Denham, S., \& Dunsmore, J. (2001). Affective social competence. Social Development, 10(1), 79-119. doi:10.1111/14679507.00150

Laible, D. (2004). Mother-child discourse about a child's past behavior at 30-months and early socioemotional development at age 3. Merrill-Palmer Quarterly, 50, 159-180. doi:10.1037/00121649.40.6.979

Macedo, L. R. (2011). Conversações sobre experiências envolvendo emoções no contexto familiar e o desenvolvimento de pré-adolescentes (Tese de doutorado, Instituto de Psicologia, Universidade Federal do Rio Grande do Sul, Porto Alegre, RS, Brasil).

Macedo, L. R., \& Sperb, T. M. (2007). O desenvolvimento da habilidade para narrar experiências pessoais: Uma revisão da literatura. Estudos de Psicologia (Natal), 12(3), 233-241. doi:10.1590/ S1413-294X2007000300005

Macedo, L. R., \& Sperb, T. M. (2008). Desenvolvimento da habilidade para narrar a própria experiência. In M. R. Maluf \& S. R. Guimarães (Eds.), Desenvolvimento da linguagem oral e escrita (pp. 45-68). Curitiba, PR: Editora da Universidade Federal do Paraná.

Macedo, L. R., \& Sperb, T. M. (2013a). Experiências de vida na conversação entre pais e filhos pré-adolescentes. Interação em Psicologia, 17(3), 235-246. doi:10.5380/psi.v17i3.25263

Macedo, L. R., \& Sperb, T. M. (2013b). Regulação de emoções na pré-adolescência e influência da conversação familiar. Psicologia: Teoria $e$ Pesquisa, 29(2), 57-64. doi:10.1590/S010237722013000200002

McAdams, D. (2001). The psychology of life stories. Review of General Psychology, 5(2), 100-122.

McKeough, A., \& Genereux, R. (2003). Transformation in narrative thought during adolescence: The structure and content of story compositions. Journal of Educational Psychology, 95(3), 537552. 
Nelson, K., \& Fivush, R. (2004). The emergence of autobiographical memory: A social cultural developmental theory. Psychological Review, 111(2), 486-511. doi:10.1037/0033$-295 X .111 .2 .486$

Ochsner, K. N., \& Gross, J. (2005). The cognitive control of emotion. Trends in Cognitive Sciences, 9(5), 242-249. doi:10.1016/j.tics.2005.03.010

Olson, D. (2003). Circumplex Model of Marital \& Family Systems. Journal of Family Therapy, 22(2), 514-547.

Peterson, C., \& McCabe, A. (1994). A social interacionist account of developing decontextualized narrative skill. Developmental Psychology, 30(6), 937-948. doi:10.1037/00121649.30.6.937

Peterson, C., \& Roberts, C. (2003). Like mother, like daughter: Similarities in narrative style. Developmental Psychology, 39(3), 551-562. doi:10.1037/0012-1649.39.3.551

Reese, E., Bird, A., \& Tripp, G. (2007). Children's self-esteem and moral self: Links to parent-child conversations regarding emotion. Social Development, 16(3), 460-478. doi:10.111/j.14679507.2007.00393.x

Ribeiro, M. O., \& Ciampone, M. H. T. (2002). Crianças em situação de rua falam sobre os abrigos. Revista da Escola de Enfermagem da USP, 36(4), 309-316.

Sales, J. M., Fivush, R., Parker, J., \& Bahrick, L. (2005). Stressing memory: Long-term relations among children's stress, recall and psychological outcome following hurricane Andrew. Journal of Cognition and Development, 6(4), 529545. doi:10.1207/s15327647jcd0604_5
Smith, V. H., Bordini, G. S., \& Sperb, T. M. (2009). Contextos e parceiros do narrar de crianças na escola infantil. Psicologia: Reflexão e Crítica, 22(2), 181-190.

Troy, A. S., \& Mauss, I. B. (2011). Resilience in the face of stress: Emotion regulation as protective factor. In S. M. Southwick, B. T. Litz, D. Charney, \& M. J. Friedman (Eds.), Resilience and mental health: Challenges across the lifespan (pp. 30-44). New York: Cambridge University Press.

Wilson, A. E., \& Ross, M. (2003). The identity function of autobiographical memory: Time is on our side. Memory, 11(2), 137-149. doi: $10.1080 / 741938210$

Zaman, W., \& Fivush, R. (2011). When my mom was a little girl... : Gender differences in adolescents' intergenerational and personal stories. Journal of Research on Adolescence, 21(3), 703-716. doi:10.1111/j.1532-7795.2010.00709.x

Zanetti, S. A., \& Gomes, I. C. (2011). A fragilização das funções parentais na família contemporânea: Determinantes e consequências. Temas em Psicologia, 19(2), 491-502.
Recebido: 27/01/2014

$1^{a}$ revisão: 03/09/2014

$2^{a}$ revisão: 19/09/2014

Aceite final: 23/09/2014 